\title{
Representaciones diversas sobre lo intercultural en una comunidad escolar
}

\author{
Various representations about \\ interculturality in a school community
}

\author{
Ramiro Catalán Pesce*
}

Este texto analiza las representaciones que construyen estudiantes secundarios sobre el proyecto educativo intercultural que ha elaborado la institución escolar a la que asisten en Santiago de Chile. La investigación fue desarrollada con una perspectiva cualitativa basada en entrevistas, conversaciones y observaciones en el trabajo de campo etnográfico en esta escuela durante tres años. El artículo muestra el proceso contradictorio de categorización y diferenciación que realiza la escuela respecto a los estudiantes signados como sujetos que pueden ser discriminados, y analiza las representaciones que surgen desde los estudiantes sobre el proyecto intercultural y sus aristas. Este proyecto educativo tiene el objetivo de reducir las posibilidades de discriminación. La complejidad de este proceso para gestionar la diversidad hace emerger no solo un nuevo clima escolar más cercano a una inclusión de carácter intercultural, sino que también permite apreciar tensiones, contradicciones y apropiaciones simbólicas distintas que surgen en toda la comunidad escolar.

This study analyzes the representations that elaborate high school students about the intercultural educational project that has been developed by their school in Santiago, Chile. The research presents a qualitative methodology based on interviews, conversations, and observations framed in ethnographic fieldwork carry out in the school for three years. This paper will examine the contradictory process of categorization and differentiation that a school perform about students identified like potentially discriminated subjects. Then, it is analyzed the representations elaborated by students about the intercultural project of their school. Although the main aim of the analyzed educative project was to reduce the possibilities of discrimination to students, this study shows the complexity of the process developed by schools to manage the existing diversity on classrooms does arise not only a new school climate but also tensions, contradictions, and various symbolic appropriations among members of the school community.

\section{Palabras clave:}

Educación, inclusión, intercultural, diversidad, investigación educativa

\section{Keywords:}

Education, inclusion, intercultural, diversity, educational research

Recibido: 15 de febrero de 2019. | Aceptado para su publicación: 3 de septiembre de 2019. Recuperado de: https://sinectica.iteso.mx/index.php/SINECTICA/article/view/955 doi: 10.31391/S2007-7033(2019)0053-010

Sección: Investigaciones temáticas

\footnotetext{
* Doctor en Diversidad Cultural y Ciudadanía, Perspectivas desde la Antropología Social, por la Universidad Complutense de Madrid. Investigador de la línea Ciudadanía y Educación del Centro de Investigación para la Educación Inclusiva (Proyecto CONICYT CIE 160009). Pontificia Universidad Católica de Valparaíso, Chile. Líneas de investigación: educación, interculturalidad y ciudadanía. Correo electrónico: ramiro.catalan@pucv.cl
} 


\section{ANTECEDENTES}

L

a investigación etnográfica que da sustento a este artículo se desarrolló en un liceo, institución educativa secundaria, ubicado en Santiago de Chile. Este contexto urbano en el que se desenvuelve el proyecto de educación intercultural marca una de sus primeras particularidades, pues, en su gran mayoría, los programas de educación de carácter intercultural en el país se han implementado en las últimas décadas en el espacio rural (Bolados, 2006; Donoso, Contreras, Cubillos y Aravena, 2006; Hevia, 2005).

Por otra parte, el proyecto en esta escuela obedece a una iniciativa que surge desde la propia comunidad escolar, en específico desde un par de profesoras que reconocen su origen mapuche y que desde ese reconocimiento levantan la necesidad de elaborar un proyecto educativo que valore la presencia de estudiantes pertenecientes a pueblos originarios (según la categorización asignada por la Ley Indígena 19.253). Esta característica contrasta con el carácter vertical, centralista y ministerial que han tenido gran parte de las iniciativas de programas interculturales emprendidos principalmente por el Estado chileno a través del Ministerio de Educación (Cañulef, 1996, 1998; Chiodi y Bahamondes, 2001; Hernández, 2004; Hevia, 2005; Williamson, 2004, 2012).

Las investigaciones recientes sobre proyectos interculturales desarrollados en contextos educativos en Chile señalan que el devenir de estas iniciativas suele estar asociado a programas folklorizantes, patrimonializantes y que reducen la valoración de las identidades étnicas al focalizarlas al espacio de un par de asignaturas en las que se muestran elementos supuestamente característicos de estos pueblos o también a la organización de "ferias interculturales" en las que se despliega un muestrario de objetos que parecieran buscar sintetizar la complejidad cultural de estas identidades (Catalán, 2013, 2016; Bolados, 2006; Treviño, Morawietz, Villalobos y Villalobos, 2018; Stefoni, Stang y Riedemann 2016; Williamson, 2012).

Aunque en el caso de la escuela donde se realizó la investigación apreciamos algunas de estas características, también observamos el interés por generar un espacio de inclusión educativa ampliado a toda su comunidad escolar y no solo a los estudiantes de origen mapuche o extranjeros. Esta inclusión está vertebrada en el carácter intercultural y de respeto a la diversidad que propugna en los distintos espacios de la escuela (Catalán, 2016).

El proyecto intercultural de esta escuela no es ajeno a la tensión por reproducir prácticas habituales a la educación homogeneizante y monocultural que ha marcado no solo el sistema educativo chileno, sino que también latinoamericano durante el siglo pasado (Dietz, 2003; Hevia, 2005; Szulc, 2009; Del Pópolo, 2017) y que, a la vez, trata de incorporar discursos y acciones que valoren la diversidad cultural. Si bien esta tensión se enmarca en lo que Tubino denomina "interculturalidad funcional" (2005), que se caracteriza por incorporar ciertos elementos interculturales al espacio escolar, pero sin deconstruir el entramado de relaciones de dominación y jerarquización que lo han constituido históricamente. También surgen algunos gestos o declaraciones discursivas al interior de la comunidad escolar que se podrían asociar a una mayor cercanía con la interculturalidad crítica (Ferrao, 2010; Tubino, 2005; Walsh, 2008).

Sin duda, este espacio escolar se constituye como un campo de disputas y negociaciones respecto al carácter intercultural con que se buscará dotar al proyecto, 
donde el grado de profundidad en su potencial transformador de prácticas y espacios más inclusivos se visibiliza en las tensiones que surgen en las categorizaciones de los docentes y en las representaciones de sus estudiantes.

Probablemente, Durkheim es el pionero del concepto de representación, al referirse a este para aludir a esas ideas colectivas que se tornan definitorias del modo de pensar de los individuos. Esas representaciones colectivas las considera como realidades estables y universales, a diferencia de las representaciones individuales, vistas como inestables y cambiantes.

Las representaciones colectivas identificadas por Durkheim como idearios complejos (arte, religión, moral) son las que determinan las representaciones de los individuos, como una exterioridad fundante y objetivadora de las creencias, pensamientos y acciones de los individuos. En este sentido, los sujetos tienen solo un rol pasivo como receptores de estas representaciones colectivas (Araya, 2002). Ese rasgo mecanicista es el que critica Moscovici (1979) para reconfigurar el concepto como representaciones sociales que destaca la mutua influencia entre lo social y lo individual, en la cual los sujetos no son pensados como meros receptores de las representaciones colectivas; más bien ellos mismos reproducen y resignifican, de modo interactivo, las representaciones a través de un proceso complejo.

Lo anterior da inicio a una corriente teórica de la psicología social que aborda las modalidades en que se estructura ese tipo de pensamiento, y relaciona procesos complejos de interacción individuo y grupo, subjetividad y objetivación, y agencia y estructura (Abric, 2001; Moscovici, 1979, 1986; Jodelet, 2000, 2003; Rodríguez, 2007).

No obstante, en la aproximación a los discursos y las prácticas presentes en la comunidad escolar emplearemos una conceptualización de las representaciones más vinculada a una mirada crítica y poscolonial que tensiona lo nacional y lo étnico, una dialéctica que es parte constitutiva de la conformación del campo intercultural. En este sentido, Hall (citado en Restrepo, 2004) sitúa su reflexión en el vínculo entre las representaciones y las identidades, pues no podrían ser entendidas de manera separada. Más que producto de la historia y las tradiciones, las representaciones pueden entenderse como un dispositivo para producir, discursivamente y en la práctica, esa historia y esas tradiciones.

Las representaciones van a estar relacionadas con la ideología, porque están inmersas en los procesos de identidad de los sujetos, al seleccionar ciertos símbolos, significados e imágenes para condensar un sentido de pertenencia. Las representaciones nunca serán azarosas; siempre van a querer decir algo:

Las políticas de la representación de las identidades refieren a la "producción" de tradición, memoria, pasado y locaciones sociales porque el pasado no está esperando a ser "descubierto", así como la memoria social o la tradición no son pura y simple continuidad desde tiempos inmemoriales (Hall, 1997b, p. 58). Estas políticas combinan tanto el silencio y la palabra como el olvido y la memoria (Hall 2001, p. 283) (citado en Restrepo, 2004, p. 61).

Lejos de ser un espacio plagado de consensos, las representaciones se constituyen en procesos de tensión entre sujetos y grupos. El contexto social, en que se despliegan sus posiciones y sus poderes diferenciados, es significativo para la producción 
de esas representaciones y, también, para posibilitar los procesos de naturalización de las construcciones identitarias.

El cómo se representa al otro "imaginariamente" es estratégico y posee una intencionalidad. Incluso en procesos de carácter crítico y contestatario, en los que se pone en cuestión un orden social específico, el proponer nuevas representaciones para reemplazar aquellas cuestionadas es parte de un "esencialismo estratégico" como el que refiere Spivak (2003). Estas nuevas representaciones no anularán o debilitarán el orden anterior, de modo necesario; por el contrario, pueden llegar a reforzarlo si se constituyen en torno a cierta lógica esencialista. Desde esa complejidad, indagamos las categorizaciones y representaciones que surgen en esta comunidad educativa.

\section{ASPECTOS METODOLógicos}

Este artículo es fruto de una investigación doctoral, de 2016, realizada durante tres años en una escuela secundaria o liceo, ubicada en una comuna de bajos ingresos económicos en la periferia de la ciudad de Santiago de Chile. Esta institución educativa contaba con una matrícula de casi doscientos estudiantes distribuidos en cuatro niveles de primero a cuarto de enseñanza media, con edades que fluctuaban de los catorce a los dieciocho años. Del total de estudiantes, unos quince jóvenes se reconocían como parte del pueblo mapuche, mientras un número similar de estudiantes provenían del extranjero, desde donde habían migrado con sus familias.

La investigación se basó en el método etnográfico (Guber, 2001; Hammersley y Atkinson, 2003), entendido como una perspectiva metodológica comprehensiva para abordar las acciones sociales y los significados que subyacen en las relaciones sociales desde el propio contexto que le da sentido; es decir, es más que un conjunto de técnicas de investigación cualitativas enfocadas a lo discursivo y a las prácticas sociales cotidianas.

Lo etnográfico alude, como punto de partida, a la necesidad de acceder a la vida cotidiana de un grupo o comunidad para poder profundizar en las dinámicas que tienen relevancia en términos sociales. Ese contacto de primera mano con la realidad observada permite abordar las rutinas y, de modo tentativo, ahondar en el tipo de relaciones intersubjetivas que se despliegan en ese espacio cargado de símbolos (Franzé, 2007; Geertz, 1987; Hymes, 2006; Velasco, García y Díaz de Rada, 2006).

En el trabajo de campo, entrevistamos individualmente a docentes, educadores tradicionales, directivos y personal de la escuela secundaria. También, hicimos observaciones participantes y no participantes (Guber, 2001) en los diversos espacios de la escuela, así como entrevistas grupales y conversaciones informales con estudiantes.

Los datos etnográficos producidos se procesaron con el análisis de contenido, sin software cualitativo. En el proceso surgieron categorías de análisis emergente sobre diversos temas vinculados a las representaciones sobre lo intercultural y lo étnico en el espacio escolar. Para el contexto de este artículo, desarrollamos dos redes de categorías que condensan los discursos y las prácticas de distintos actores de la escuela. Por una parte, respecto a los docentes y educadores tradicionales, exploramos el proceso de categorización que realizan con los estudiantes de origen mapuche para focalizar en ellos el trabajo de interculturalidad. Esto redunda en una serie de paradojas que aparecen con el afán de identificar a aquellos jovenes. Por otra, 
un segundo grupo de categorías son elaboradas por los estudiantes y despliegan las distintas representaciones que pueden producirse en el cotidiano escolar como respuesta al proyecto intercultural de la institución educativa.

\section{EL PROCESO DE CATEgoRIZACIÓN DEL ESTUDIANTADO}

El proyecto intercultural de esta institución educativa se construye con la intención de evitar la discriminación hacia el estudiantado perteneciente al pueblo mapuche y también al de familias extranjeras que se fueron incorporando poco a poco a la escuela. Para ello, creó una serie de instancias que pretenden fomentar un sentido de valoración de la diversidad cultural en su comunidad escolar; por ejemplo, instauró cuatro cursos obligatorios orientados a pueblos indígenas, que, de manera indistinta, denominaba "cursos de culturas" dentro de la escuela.

Los cuatro cursos eran de culturas madres (del área andina y mesoamericana), cultura mapuche, cultura rapa nui y cultura aymara, que se organizaban como un curso por nivel educativo, de primero a cuarto medio. Los docentes que los impartían eran llamados "talleristas", pues no contaban con un título de profesor, salvo en el caso de la encargada del área intercultural (que también daba el curso de culturas madres), que coordinaba tanto el quehacer de estos cursos como las distintas actividades que se ofrecían durante el año escolar con un sentido intercultural.

En el caso del curso de cultura mapuche, era un educador tradicional mapuche quien lo dictaba, similar al de cultura aymara, que impartía una educadora tradicional de ese pueblo. Por su parte, el educador del curso de cultura rapa nui, si bien reconocía no ser descendiente de este pueblo, sí manifestaba su cercanía, conocimiento y experiencias como algo que lo validaba, pues había vivido durante muchos años en la isla y había aprendido su lengua y sus costumbres.

En la misma línea, el proyecto intercultural consideraba tres hitos de actividades durante el año: una jornada de sensibilización en marzo para los estudiantes de primer año medio que recién se integraban al liceo; la celebración del año nuevo indígena en junio; y la conmemoración del 12 de octubre mediante una "feria intercultural". De igual modo, se organizaba una puesta en escena intercultural en los espacios comunes de la escuela, en la que se visibilizaban símbolos y elementos de distintos pueblos; por ejemplo, un moai de Rapa Nui, la bandera aymara, o un rehue mapuche.

En ese contexto, desde el ámbito de docentes y educadores tradicionales, surgen ciertos mecanismos de categorización para identificar y diferenciar a aquellos estudiantes en riesgo de ser discriminados. Una de las primeras acciones que lleva a cabo la dirección del liceo, junto con la coordinadora del área intercultural, es identificar a comienzos de cada año a los estudiantes que pueden ser considerados en estas categorías:

Recibí también la hoja del orientador el viernes y me la dio firmada con todos los descendientes [de mapuches] que hay y todos los inmigrantes. Y yo en mi cabeza tengo como una idea preliminar de lo que tengo que hacer, pero no tengo escrito el trabajo. Yo creo que va a ser una dinámica de todo el año. Tengo que a lo mejor formar trabajo cada quince días o una vez al mes trabajar con ellos (profesora M, coordinadora intercultural).

En el trabajo de campo observamos que, en el marco del proyecto intercultural, lo primero que hace la institución educativa para categorizar a un estudiante como 
mapuche es reconocer si posee alguno de sus dos apellidos mapuches. Un segundo criterio es fijar la atención sobre aquellos estudiantes que, si bien no tienen apellido mapuche, igualmente comienzan a participar en las actividades interculturales del liceo, o bien, pueden mencionar en alguna conversación con los docentes o educadores tradicionales que provienen de una familia con ancestros mapuches:

No se trata de que los alumnos se conviertan en mapuches, no; pero que tengan [...] Si son de apellido mapuche [...] obviamente se trabaja un poco más diferente con ellos, porque de hecho a ellos se les aparta. Se les da otro tipo de incentivos de educación, para que ellos se valoren como tal (educador tradicional, curso de cultura mapuche).

Este educador, que se reconoce como mapuche, pone en cuestión la intencionalidad de "convertir" a los estudiantes en mapuches. Sin embargo, por otro lado, hace explícita la atención que se dirige hacia esos jóvenes como destinatarios del proyecto intercultural. Así, surge de manera clara un marcador étnico, relacionado con el portar un "apellido mapuche", lo que deviene en focalización y diferenciación. La mención a que "se les aparta" es bastante significativa en ese aspecto. Implicada en este proceso de categorización también emerge la ambigüedad de que, aunque no se espera que los estudiantes se transformen en mapuches, sí que "se valoren como tales".

Es paradójico que, si en el escenario anterior a la implementación del proyecto intercultural, había estudiantes que podían discriminar a sus compañeros, en el nuevo es la propia institución escolar la que entra en el juego de marcar diferencias entre estudiantes mapuches y aquellos que no lo son; los identifica y focaliza para trabajar con ellos y, así, evitar su exclusión, pero en el cotidiano los distinguen como diferentes:

Y se han logrado cosas positivas con los alumnos, por ejemplo, hay varios alumnos que son de origen mapuche y ya se sienten con ese valor, ya se sienten que son mapuches. Obviamente con tener el apellido mapuche no significa que sea mapuche, porque tiene el apellido, pero no tiene el valor que se puede sentir como mapuche. Entonces lo que tratamos de hacer nosotros, este equipo de trabajo que tenemos acá, es que ese alumno mapuche, nacido y criado aquí en Santiago como el resto, cómo uno más nomás, que pueda valorarse y que pueda sentirse como mapuche. Ese es el objetivo (educador tradicional, curso de cultura mapuche).

Para responder a la pregunta ¿cómo reforzar la identidad de los alumnos en riesgo de ser discriminados?, el proyecto intercultural diferencia a los alumnos individualizándolos a partir de marcadores que remiten a su origen (indígena o extranjero). En el caso de los alumnos categorizados como mapuches, ya mencionamos que será su apellido el que configure su marca étnica, y de ahí en más serán incorporados a procesos de reconocimiento y revalorización de su olvidada (o negada) pertenencia étnica.

Relevante en este punto es la propia mención del educador tradicional que realiza el curso de cultura mapuche sobre que el apellido no basta para sentirse mapuche. Valorarse y sentirse mapuche requerirá ciertos mecanismos que generen un sentimiento de afinidad con esa identidad étnica. Se apela, entonces, a lo que Bloul (1999) denomina "políticas emocionales de la identificación" para que esos estudiantes se reconozcan como mapuches:

Mientras me preparo la taza de café en la biblioteca, lugar de reunión de los profesores y talleristas del área intercultural, éstos comienzan a conversar sobre la planificación del año nuevo indígena. Lo primero que señala la coordinadora intercultural es que no le parece buena idea hacer un desayuno exclusivo para los alumnos mapuche. El educador 
tradicional mapuche asiente con la cabeza mostrando su acuerdo con eso. Los demás siguen escuchando. "Además que la idea no es forzarlos a que se reconozcan como mapuche, ¿cierto?", prosigue con un tono de voz suave la coordinadora como si ella también tratara de convencerse (notas de campo, abril de 2012).

Lo anterior refiere a una de las actividades que se realizaba en la escuela en años anteriores, un desayuno al que se invitaba a todos los alumnos con ascendencia mapuche y que, por solicitud expresa de la coordinadora intercultural, se suspendió, pues ella lo consideraba una instancia que marcaba diferencias con los demás estudiantes:

Eso me contaba el director, que habían intentado hacer esto, pero los sacaban como a un desayuno o algo así. Y yo creo que ahí discrepo un poco, porque ellos tienen que partir reconociéndose un poco ellos y no [...] Creo [que] se reconocen a partir de estos diálogos, a partir de conversaciones cercanas, más que darles un desayuno porque es año nuevo [indígena] y están bajo esa dinámica. También me parece que tiene que trabajar todo el colegio en eso. Y yo, a partir de que también van a ser agentes socializadores en su curso, entonces va a ser algo como un escándalo, y no pretendo hacer un ghetto de esto (profesora M, coordinadora intercultural).

La instancia del desayuno focalizado en los estudiantes descendientes de pueblos indígenas generaba desconfianza en la coordinadora intercultural debido a la diferenciación y el encapsulamiento que parecía implicar su realización y que se distanciaba de un sentido más transversal de trabajar la interculturalidad en todos los ámbitos de la escuela.

Es significativo que la coordinadora plantee como alternativa una estrategia en la que el reconocimiento propio de los estudiantes como mapuches surja desde la posibilidad de participar en diálogos y conversaciones insertas en el cotidiano de la escuela. Esto va a implicar una complementariedad con aquellas actividades específicas marcadas como significativas en el proyecto intercultural de la institución educativa, como la celebración del año nuevo indígena, y que se constituya esta dualidad, actividades específicas y prácticas cotidianas, como una opción para implementar el proyecto intercultural de una manera dialogada con los estudiantes y que estos tengan la expectativa de convertirse en "agentes socializadores en su curso" como espera la coordinadora.

La comentada invitación a este desayuno también podía implicar forzar en algunos estudiantes de apellido mapuche la obligatoriedad de reconocerse como tales y hacerse cargo de un proceso de reconocimiento identitario que, quizá, les generaría más conflicto que adhesión y que, en cierto modo, aceleraba una dinámica de recuperación de una memoria histórica y de un sentido de pertenencia que no puede despertarse por decreto ni tampoco con la mera invitación a un desayuno. Esto, sobre todo, al pensar en toda una historia de colonialismo que ha generado dinámicas de silenciamiento, olvido y negación por parte de sus familias, tal vez para evitar la discriminación y la segregación histórica que en Chile ha existido hacia los pueblos indígenas:

Matías: A mi mamá de repente, de hecho, [le preguntaba] ¿de qué onda con mi apellido [mapuche]? Porque antes le preguntaba eso [...] Cuando empecé a investigar sobre la cosa, y poco y nada me dijo porque ella no sabe mucho [...]. Si yo fui el que anduve investigando, leyendo libros y toda la onda. [...] Y después me descubrí, mi nombre es del sur (entrevista grupal a estudiantes).

De nuevo, aparece el carácter paradójico de este proceso que buscaba generar espacios de valoración y discriminación positiva basados en una identificación étnica 
fomentada desde la institución escolar para evitar potenciales conflictos entre los estudiantes. Esto implicaba, en esencia, enfrentar el temor a la discriminación y la exclusión en el espacio escolar, al desarrollar un proceso de diferenciación y particularización de ciertos sujetos dependiendo de si poseían o no una marca asociada a su etnia (el apellido) o a su nación (su lugar de origen) en los estudiantes migrantes, cuyo caso no trataremos en este artículo.

También, entrelazado a estas dinámicas complejas y a menudo contradictorias, surge la posibilidad de gatillar un descubrimiento familiar como señala el estudiante en el testimonio anterior: la recuperación de una memoria colectiva, que implica reunir paulatinamente piezas de un pasado fragmentado, cuando no olvidado:

Creo que [ese tipo de desayunos] se contrapone a la visión intercultural que yo creo [...] que pienso. Entonces no quiero hacer eso. Tampoco creo que para el We Tripantu [año nuevo mapuche] tengamos que hacer desayuno aparte. Como algunos colegas me comentan, que este año pagan los profesores almuerzo aparte, y los alumnos aparte. Entonces yo dije: "No po', si ese día se hace una fiesta todos comemos en fiesta, cuando uno va a un matrimonio o a una fiesta o a una ceremonia, no comemos en mesas separadas". Entonces ahí yo tengo que partir de esto en las reflexiones pedagógicas. Yo ahí dar mi opinión y tratar de disuadirlos para que tengas una mesa té club [todos juntos] (profesora M, coordinadora intercultural).

Esta labor, percibida como compleja por los docentes y talleristas más cercanos al trabajo de interculturalidad, de focalizar a los alumnos susceptibles de ser discriminados, pero que, a la vez, marca una condición indígena incluso en aquellos alumnos que no se perciben de ese modo, se vincula a una representación que algunos profesores y directivos de esta escuela enunciaron alguna vez. La imagen de "inyectarles" el cariño por su cultura a fin de generar una suerte de inmunidad ante la discriminación es una representación que ha aparecido también en investigaciones en otros contextos culturales (Catalán, 2013):

Yo trabajo en forma general en el curso, pero aquí, por ejemplo, este es un equipo de trabajo, tenemos una coordinadora [...] que toma los alumnos, a los mapuches, con origen mapuche. Entonces ella le hace un incentivo o una, ¿cómo le llaman, una...?, para que el alumno pueda, ¡como una inyección del tema aparte! Ella con su propia estrategia, la valorización, que se valoren los chiquillos. Entonces en ese [...], por ese lado (educador tradicional, curso de cultura mapuche).

Esta representación juega con una metáfora que corporeíza ciertos procesos de etnogénesis, relativos a producir la reapropiación de un pasado olvidado o negado por parte de sujetos que van a reposicionarse desde una identificación étnica que se construye en torno al resurgimiento de algo perdido.

La referencia a la "inyección" es muy interesante, pues se vincula a dos niveles analíticos: por una parte, implica una suerte de "biopolítica" (Foucault, 1987), que alude a la posibilidad de las instituciones de intervenir los cuerpos para programar y administrar sus acciones sociales; en este caso, "inyectar" la valoración de los estudiantes y de su pertenencia étnica, como si aquello fuese a desencadenar una serie de transformaciones identitarias. Por otra, la representación de la inyección que puede crear una inmunidad en el estudiantado mapuche frente a la discriminación opera en un sentido similar al dado por Esposito (2005), con su concepto de immunitas, mediante el cual expone cómo la lógica inmunitaria que se despliega en la sociedad contemporánea rompe la posibilidad del vivir juntos, de la comunidad. 
Una nueva paradoja emerge acá, esa búsqueda de protección frente a la discriminación, que se sustenta en la valoración de lo propio, puede implicar el distanciamiento con el otro y la imposibilidad de formar comunidad con sujetos diversos. La amenaza del gueto, que planteaba la coordinadora intercultural en una cita anterior, puede ser consecuencia también de la diferenciación y la focalización.

Volviendo al tema de cómo la institución escolar va a ir identificando a los estudiantes que serán categorizados como mapuches, surge la denominación coloquial por parte de sus propios compañeros que, a menudo, los señalan como "los mapuches", al hacerse eco de esa diferenciación. Aquí un punto relevante, pues las categorizaciones que produce la institución escolar también son percibidas y procesadas por los demás estudiantes para elaborar sus propias representaciones sobre lo intercultural, como lo mostraremos en el siguiente apartado.

De esto surgen opiniones como las de un estudiante que, en una clase que pudimos observar, le reclamaba al profesor que siempre sacaban de la sala "a los mapuches" para ir a entrevistas u otras actividades, y no a él. Aunque pudimos percibir que el reclamo de este joven tenía una intención más cercana a evadirse de clases que a ser una demanda de igualdad (a no ser que también se entendiera como el derecho igualitario a evadirse del aula), es significativo el hecho de que para otros estudiantes era notoria la diferencia que marcaba la escuela respecto a aquellos jóvenes que sí eran reconocidos como mapuches.

En un caso similar, una estudiante señalaba que, como no era mapuche, a ella la "discriminaban", pues no la invitaban a participar en ciertas actividades que se llevaban a cabo en el liceo y en las que sí participaban estudiantes mapuches y migrantes. Esta última opinión esboza la sensación de ciertos jóvenes de estar fuera del radio de interés de la institución escolar, pues perciben que, al no pertenecer a un pueblo indígena o no ser migrantes, no son parte de las otredades que la institución escolar focaliza como relevantes.

Del mismo modo, esta opinión se puede volver recurrente, aunque no necesariamente sea cierta, pues, en las ceremonias y actividades que observamos en el trabajo de campo, la mayor parte de las veces participó un grupo diverso de estudiantes tanto mapuches como no mapuches y migrantes. El común denominador pasaba más por su vocación de participación y su "talento artístico" que por su selección a partir de ciertas marcas étnicas o de nacionalidad. De hecho, el grupo de jóvenes que más intervenía solía ser siempre el mismo, pues practicaban cada semana las danzas, canciones y actividades vinculadas a la puesta en escena de esa interculturalidad que el liceo buscaba destacar.

\section{SOBRE LAS REPRESENTACIONES QUE ELABORAN ESTUDIANTES}

En este apartado presentamos las variadas representaciones que elaboran tres grupos de estudiantes con distintos niveles de participación en las actividades interculturales de su escuela. Emergen categorías de análisis que condensan la diversidad y heterogeneidad de representaciones que configuran los jóvenes desde diferentes subjetividades sobre el proyecto intercultural. No está de más señalar que el estudiantado puede compartir representaciones que, en apariencia, suelen parecer contradictorias. De igual modo, pueden situarse en posiciones cambiantes y, desde 
esos vaivenes, construir representaciones ambivalentes; es decir, dependiendo del momento y el contexto en que se posicionen, los jóvenes podrán ubicarse en más de un grupo, incluso en alguno no mencionado aquí. De ahí el carácter complejo de estas representaciones en procesos de producción y reproducción: mientras algunas parecen más fijas y consolidadas, otras se perciben oscilantes y ambiguas.

\section{Grupo de estudiantes que participan en las actividades interculturales}

Este grupo se caracteriza por participar durante todo el año escolar en una serie de actividades de carácter intercultural que la institución educativa sitúa como claves para la puesta en escena de su proyecto intercultural: presentaciones musicales, bailes, muestras de folklore, gastronomía y otras acciones que suelen desarrollarse en hitos como la celebración del año nuevo indígena, la conmemoración del 12 de octubre u otras instancias.

El estudiantado que conforma este grupo ensaya y practica semanalmente en distintos talleres llevados a cabo por los educadores tradicionales, que manifiestan, de manera permanente, su motivación por el enfoque intercultural del proyecto del liceo. Asimismo, sus participantes son jóvenes de origen mapuche o migrante, pero también otros estudiantes que, sin tener una pertenencia étnica declarada, demuestran su compromiso constante de aportar a esas actividades.

"La guarida salvavida"

Ismael: Yo también escribo y yo catalogué a este liceo como la guarida salvavida.

Ramiro: ¿Guarida salvavida?

Ismael: Sí, porque es una guarida donde uno puede esconderse del miedo y salvavida porque aquí también hay niños que tienen sus problemas y aquí se pueden apoyar y salir adelante, y de esta manera se pueden salvar algunas vidas (entrevista grupal).

Este estudiante, en su representación de la "guarida salvavida", condensa simbólicamente la percepción extendida entre sus pares de que el liceo sirve como una contención social, un refugio donde pueden desarrollar ciertos intereses y no se les va a discriminar ni a juzgar. Su referencia a ese lugar protector donde puede transformarse la escuela también alude a esa noción de immunitas (Esposito, 2005), pues implica una separación del mundo social, inmunizarse de los problemas y los miedos. Esta situación conlleva otro riesgo: aislarse del contexto externo a la institución escolar.

En ese sentido, el contexto de segregación urbana que rodea a esta escuela y en el cual viven la mayoría de sus estudiantes genera un sentido de vulnerabilidad y desprotección que, en contraste, hace emerger la percepción de esta comunidad educativa como un espacio valorado, pero que puede presentarse como una suerte de burbuja desconectada del entorno. 
"Los pueblos marginados"

Ismael: Sí, cantó una coreografía, y después hizo un canto rapeado, y ahí hablaba de los mapuches.

Francisco: Ah, y una vez cuando cantaste una canción nada que ver con el rap.

Daniela: Ah, la de Shakira, que era para un baile.

Ismael: Esa fue la primera.

Daniela: Y después cantamos con Ismael la de los mapuches, que se llamaba Pueblos marginados, porque son muy marginados aquí los mapuches, por eso le pusimos ese nombre (entrevista grupal a estudiantes).

La representación que alude a la marginación del pueblo mapuche permite a estos jóvenes elaborar una crítica que, hasta cierto punto, podemos plantear como de subalternidad (Spivak, 2003), ya que expresa sin ambigüedades la exclusión histórica que este pueblo ha vivido en la sociedad chilena. Es interesante que estos dos jóvenes no sean de familia mapuche y, aun así, muestran en su canción un sentido de solidaridad y compromiso con la situación de los pueblos indígenas. Es, en cierto sentido, una expresión muy clara del tipo de relación intercultural que el proyecto del liceo trata de crear en sus estudiantes.

Por otra parte, también se hace evidente la capacidad de los jóvenes de recurrir a manifestaciones artísticas variadas para elaborar sus representaciones de lo intercultural, y manejar con creatividad aquellas expresiones que les son más cercanas. Así, aparecen las subjetividades múltiples de los estudiantes, tributarias de diversos contextos, y que hacen posible articular el gusto musical por Shakira, la denuncia sobre la discriminación étnica, y el uso de corrientes musicales como el hip hop, producidas en otras culturas.

A continuación, transcribimos una parte de la canción de Ismael y Daniela (solo en este caso utilizamos los nombres reales de los estudiantes para hacer valer su autoría):

¿Qué pensamientos son los de ustedes?

Que dejan hablar a quien no deben

¿Qué se creen que critican?

¿Qué se creen que marginan?

¿Qué se creen? que se creen superior

Bueno señora y señor, les voy a contar una cosita el hip hop es lo mejor.

Por eso fue esta mi elección.

Recapaciten que estamos en el siglo XXI y aquí ninguno es perfecto.

Nuestros hermanos mapuches, esperan que los ayudemos y apoyemos para que el país los reconozca y no los trate como una mosca asquerosa.

La sociedad cada día margina más, ¿por qué no podemos ser como los demás? Los demás países que respetan a sus raíces de donde nacieron y de a poquito surgieron y 
salieron adelante en busca de una oportunidad.

Este mensaje va dedicado a los que les queda mentalidad.

Ramiro: ¿Y la letra, la hiciste tú, Daniela, con Ismael?

Daniela: 0 sea en mi parte yo, y el coro entre los dos, y una pequeña estrofa de una poesía de pueblos indígenas (entrevista grupal a estudiantes).

El tono de denuncia que plantean estos jóvenes sobre la marginación de los pueblos originarios y la jerarquización de culturas que ha imperado en la sociedad chilena adoptan un sentido casi poscolonial, pues alude a cómo un sector dominante de la nación se autopercibe superior al resto y, de ese modo, ha legitimado, históricamente, la exclusión de los pueblos indígenas y de otros grupos sociales. Esta crítica se torna más evidente al articularse con una dimensión temporal ("estamos en el siglo XXI") para señalar lo necesario que es "recapacitar" sobre esos modos de actuar y pensar que son herencia de otro tiempo, de otro siglo. De nuevo, estos estudiantes, sin ser de ascendencia mapuche, se identifican, en forma simbólica, como "hermanos" respecto a estos pueblos para denunciar el maltrato, los prejuicios y la discriminación.

También es significativo que su canción remita al tema del reconocimiento ("apoyemos para que el país los reconozca"), pues se vincula, de manera directa, con una de las principales demandas que los pueblos indígenas mantienen con el Estado chileno: la necesidad de ser reconocidos en términos constitucionales. Aquí opera, del mismo modo, la comparación que establecen estos jóvenes con la realidad de otros países de la región que sí "respetan sus raíces de donde nacieron" y que, podríamos agregar, sí han reconocido social y constitucionalmente a los pueblos indígenas.

"El respeto"

Francisco: Para respetar más.

Andrés: Porque si sabemos de dónde venimos, respetamos.

Andrés: Tenemos nuestras raíces que son los mapuches y hay que respetarlos.

Francisco: Pero no solamente a los mapuches, a todos.

Andrés: Pero es que siempre dicen los mapuches, y son muchos otros, los voy a acusar a mi mamá (risas).

Jorge: Es que siempre meten a los puros mapuches, faltan los africanos, y tantos otros (entrevista grupal a estudiantes).

Una representación, casi transversal entre los diversos actores del liceo y que también aparece en este grupo de alumnos, es la que define el respeto a la diversidad como un concepto bisagra para hacer funcionar los mecanismos de reconocimiento y valoración de la otredad. Ese discurso pareciera indicar que, sin respeto hacia lo diferente, no hay proyecto intercultural posible. Por lo tanto, la reiteración discursiva 
de este funciona casi como un mantra ("para respetar más", "hay que respetarlos”). En ese sentido, apreciamos la presencia de representaciones que no son exclusivas de un grupo específico, sino que pueden ser apropiadas por diversos estudiantes.

De manera tenue, notamos también una reflexión sobre la imagen de relacionar, casi en automático, las raíces indígenas con lo mapuche. Ante lo que otro estudiante señala: "No solamente a los mapuches, a todos", como si quisiera decir que la importancia de un pueblo originario no debe homogeneizar la diversidad cultural ni tampoco ocultar a otros grupos sociales diversos.

\section{"Un liceo que no es normal"}

Ismael: Es que la sociedad dispone de algo que es como normal, que todos los colegios deben estudiar matemáticas o lenguaje. Y esto [el liceo] está fuera de lo normal porque no todos los liceos y colegios hacen este tema de la interculturalidad. Por eso debe ser que otros niños que vienen de otros colegios llegan acá y dicen "no po', esto no es normal”. La sociedad puso que enseñar matemáticas o lenguaje es verdad. Pero aquí es normal que enseñen matemáticas, lenguaje, y todo lo demás y aparte interculturalidad como ramo. Eso debe ser el desencaje de los primero, que también llegan haciendo destrozos, pero bueno después del tiempo van madurando y van tomándole el peso al ramo y después se proyectan en sus vidas (entrevista grupal a estudiantes).

Aquí surge una representación sobre "lo normal" que puede ser, o no, una institución educativa en su modo de generar los procesos de enseñanza y aprendizaje. Se sustenta en la reflexión sobre el currículo y los diferentes tipos de contenidos que se pueden valorar al interior de una escuela. Por ello, el estudiante alude a la particularidad del liceo y su proyecto intercultural que plantea expectativas distintas sobre lo que es normal encontrar en una escuela. Lo normativo, lo uniforme, presentado y estandarizado como lo correcto, es puesto en tensión por el enfoque intercultural y su reivindicación de lo diverso que amplía las posibilidades de conocer y aprender otras tradiciones y otros saberes. En ese sentido, la "anormalidad" del liceo es vista como algo positivo, algo que la distingue y caracteriza, y algo también con lo que chocan y deben adaptarse los alumnos que recién se incorporan a este espacio escolar.

\section{Una sociedad discriminadora}

Javier: Eso po' que somos discriminadores, y se puede dar cuenta uno en la misma plaza de La Moneda [Palacio de Gobierno de Chile]. Una persona vestida de mapuche se mira altiro [al instante], pero si va una persona normal gringa nada po'.

Andrés: Lo idolatran.

Javier: Claro, poco menos. No, pero somos discriminadores, eso lo admito. No todos, pero sí la mayoría y yo creo que debería cambiarse porque todos somos iguales, todos somos personas y debemos respetarnos. Todos tenemos sentimientos, no somos animales, porque un animal puede sentir, pero no va a sentir lo mismo que nosotros (entrevista grupal a estudiantes).

La sociedad chilena es percibida como discriminadora; esta es una representación que puede encontrarse de manera transversal entre los diversos jóvenes. Un punto interesante es que Javier señala que "somos discriminadores". No lo ve como un fenómeno 
externo a él, sino que se asume como parte de ese grupo mayoritario. De ahí que, al mencionar la posibilidad de cambiar esas actitudes, probablemente también se incluya dentro de esa necesidad de cambio.

La referencia de este joven sobre el cambiar esas miradas discriminatorias muestra cómo el discurso elaborado por el proyecto intercultural va permeando a ciertos estudiantes, al grado de que estos asuman en sus enunciados la necesidad de transformación de ciertas prácticas sociales. En ese sentido, lo políticamente correcto se instalará como un discurso compartido, o reproducido, por este grupo de alumnos que participan de manera más activa en el proyecto intercultural.

La referencia a las miradas asoma con claridad en los discursos de los jóvenes. Aquel contraste que se marca sobre cómo la sociedad mira a un "gringo" ("se idolatra"), y cómo se fija la mirada de alerta en la presencia de un mapuche en las cercanías de un espacio simbólico muy potente como es el Palacio de Gobierno, hace evidente una crítica de las expresiones de discriminación incluso en aquellos entornos que debieran ser públicos y ciudadanos.

Asimismo, esta cita muestra cómo aun esas representaciones más críticas pueden albergar lógicas hegemónicas que afloran en el lenguaje; por ejemplo, cuando el estudiante señala en su discurso la diferencia entre "una persona vestida de mapuche" y "una persona normal gringa", como si la vestimenta mapuche no fuese "normal".

El tema de las miradas aparece como algo relevante, pues los jóvenes plantean que la discriminación no son solo las palabras o las acciones que se realizan, sino también situaciones más sutiles, pero de igual modo perceptibles, como el mirar o el ser mirado. Así, podemos comprender de mejor modo la reflexión de este joven que señala: "No somos animales, porque un animal puede sentir, pero no va a sentir lo mismo que nosotros". Miradas, sentimientos y emociones se entrecruzan en las experiencias de estos estudiantes que perciben la discriminación como una realidad, al punto de plantearse la necesidad de recalcar su dignidad humana.

Grupo de estudiantes que no participa activamente en las actividades interculturales, pero valora su escuela

Un segundo grupo de estudiantes se caracteriza por valorar el enfoque más intercultural de la institución escolar pese a no tener una participación activa y protagónica en las ceremonias o celebraciones. Su percepción es positiva sobre lo que consideran una marca distintiva del liceo: el esfuerzo por situar el conocimiento en los pueblos indígenas como un aspecto central en los procesos de enseñanza y aprendizaje.

"Las raíces de uno"

Ignacio: Obvio que interesante, si no me gusta o que me parezca mal sería como una ignorancia; si son las raíces de uno, está súper bien que enseñen porque la gente no sabe (entrevista grupal a estudiantes).

Es interesante cómo el proyecto intercultural logra instalar un sentido de valoración sobre el conocer más de los pueblos originarios, incluso en aquellos estudiantes que 
no reconocen una identidad étnica, pero que plantean que cuestionar este tipo de enseñanza orientada a reconocer "las raíces de uno" sería demostrar "ignorancia".

En esa tensión entre conocimiento e ignorancia, que parece estar latente en el discurso de este joven, también emerge como necesidad de enseñar aquel conocimiento que ha estado invisibilizado en el sistema educativo y en la sociedad, pues "la gente no sabe".

\section{"Una segunda oportunidad"}

Pablo: A mí también me gusta el colegio porque es como que no discriminan por niño problema, porque igual yo me portaba súper mal en el otro colegio y aquí como que se puede decir que nos dan una oportunidad y si uno la aprovecha bakan [bueno] y si no, no po' (entrevista grupal a estudiantes).

Se despliega y amplía lo especial del colegio, no solo a temáticas étnicas o migrantes, sino que a esa tolerancia por el otro, que algunos jóvenes también interpretan desde sus subjetividades y sus posiciones a menudo sujetas a estigmatización; por ejemplo, la noción de "niño problema" surge como una etiqueta que puede llevar aparejada la sensación de no contar con oportunidades. De ese modo, el espacio que daría el liceo se establece como valorado por no implicar, al menos a ojos de Pablo, una discriminación previa.

Esta representación abre un espacio educativo que la mayoría de los estudiantes valora por su sentido inclusivo, pues se pondría en juego un ambiente de mayor tolerancia y respeto no solo a la diversidad relacionada con lo étnico o lo migrante, sino que ampliado a las distintas historias de vida de los jóvenes. Sin embargo, como veremos en el siguiente apartado, también hay otro grupo de estudiantes que no tiene una visión tan positiva sobre lo inclusivo del proyecto intercultural.

\section{Grupo de estudiantes que no participan habitualmente, pero sí cuestionan el proyecto intercultural}

Hay un tercer grupo de jóvenes que se caracteriza por manifestar una visión crítica sobre la interculturalidad desarrollada en el liceo, ya sea por prometer algo que no ven que se realice en la práctica, o bien, porque se consideran excluidos de ese proyecto. Toman con distancia los discursos institucionales y las puestas en escena de lo intercultural, pues desde sus experiencias no hay mayor diferencia con lo que han vivido en otras escuelas.

\section{"Ahí quedó la interculturalidad"}

Conversando con Carolina y Muriel en el patio, les pregunto por el tema de la nueva normativa sobre los atrasos que consiste en que si un alumno llega después de las 8:30 de la mañana, será devuelto a su casa. Nuevas reglas que han motivado críticas de los alumnos y de algunos profesores al preguntarse qué harán los alumnos con su tiempo si son devueltos a sus casas. "Acuérdate, va a repetir cualquier cabro [joven], va a bajar la matrícula y van a cerrar el Liceo", le dice Carolina a su amiga. Le pregunto: “ ¿Y no han conversado con los directivos para decirles eso?" Debe haber sonado muy ingenua mi pregunta porque ella me responde, con 
ese tono inconfundible de parece-que-no-te-enteras-de-cómo-funcionan-las-cosas-aquí: "La dirección es muy cerrada”. Yo añado: “¿Y lo intercultural?" [...] "Ahí quedó lo intercultural”, me responde con desdén (notas de campo, octubre de 2012).

La idea del reglamento, de las normas, pareciera jugar en contra, a menudo, de ese aire de tolerancia que espera irradiar el proyecto intercultural. La misma chica lo señala: "Ahí quedó lo intercultural", casi connotándolo como un proyecto-objeto inerte, quieto. En definitiva, solo enunciado y no transversal.

Algunos jóvenes se posicionan con distancia frente al proyecto intercultural, a veces con actitudes implícitas, como no participar de las actividades del liceo, pero en otros casos pueden explicar su crítica a la falta de diálogo con estamentos como la dirección del liceo, sobre todo cuando están en juego temáticas que los atañen de modo directo, como la normativa sobre atrasos. En ese sentido, la pregunta sobre lo intercultural posibilitó que la joven verbalizara una imagen de lo intercultural como quieto, pasivo, a menudo desvinculado de aquellos asuntos que pueden ser importantes para algunos estudiantes.

\section{La diferenciación positiva de lo étnico}

En algunos alumnos existe la percepción de que se diferencia de manera positiva a los estudiantes de origen mapuche y se deja de lado a quienes no pertenecen a una etnia. $\mathrm{Si}$ bien estas menciones son marginales y suelen aparecer enmascaradas como bromas al pasar, puede que planteen, de manera latente, un cuestionamiento a la diferenciación que produce la institución escolar entre los jóvenes según su pertenencia étnica.

Así sucede, por ejemplo, en el caso de un estudiante que le reclama al profesor de cultura mapuche que, cuando van a jugar Palín, "está eligiendo a los mapuches nomás" y luego se larga a reír. U otro joven que, cuando un docente está seleccionando estudiantes para llevarlos a responder el cuestionario de una fundación que ha comenzado a trabajar con la escuela y que, por ello, los va a sacar del aula, señala con un dejo irónico: "Llevan a los puros mateos [estudiosos] y mapuches".

La interculturalidad focalizada

Otra representación que aparece de manera circunstancial es la que no le concede mayor diferencia a este liceo con cualquier otro y remarca, a veces, que lo intercultural no reviste mayor transversalidad:

Tres alumnos están conversando en el pasillo, afuera de la sala de clases. Acaba de terminar el curso de Mapuche, y escucho que uno de los chicos le pregunta a su compañero qué va a hacer en la feria intercultural [del 12 de octubre]. A lo que el aludido le responde que va a bailar. Aprovecho de acercarme al grupo con el que ya había conversado otras veces: “ ¿Y crees que el Liceo sea intercultural?", le pregunto a uno de los chicos que estaban conversando. "Sólo en las clases de cultura. En los otros cursos no se conversa, usted ve" (notas de campo, septiembre de 2012).

Ese carácter acotado del proyecto intercultural también es percibido por algunos estudiantes, al menos en dos planos. El primero se refiere a esa focalización en "cursos 
de culturas" que, si bien permite su inclusión como contenidos formales, obligatorios y legitimados en comparación con las demás asignaturas, redunda en su "cierre operativo". De ese modo, los contenidos de estos cursos quedan limitados al horario que disponen, y solo pueden visibilizarse fuera de ese horario en las actividades interculturales de celebración que reúne a todo el liceo en ciertas fechas. El segundo plano concierne a la imagen que queda para este alumno de que en los otros cursos no emerge lo intercultural, una idea compartida, por ejemplo, por los educadorestalleristas. Por lo tanto, el carácter intercultural del liceo quedaría en cuestión al no aparecer en todos los espacios pedagógicos.

\section{CONCLUSIONES}

Como señala Hall (2003), las políticas de representación de las identidades se juegan en un contexto de negociaciones y procesos de selección de tradiciones y memorias que implican una producción estratégica sobre lo que será nombrado o silenciado. En ese sentido, el proyecto intercultural de esta institución educativa promueve una imagen de valorización de la diferencia y la diversidad cultural al desarrollar un relato alternativo que apela al reconocimiento de los estudiantes de ascendencia indígena.

En esta línea, la escuela va a generar un proceso de categorización del estudiantado que identifica como potencialmente discriminado y que funcionará sobre un dispositivo de inclusión y exclusión paradójico. Para poder reforzar de manera positiva la pertenencia étnica o la valoración de las nacionalidades de sus estudiantes extranjeros, uno de los primeros mecanismos que va a desarrollar será el diferenciarlos. Esta construcción de categorías presenta tensiones similares a las que pueden surgir en algunas políticas de acción afirmativa sobre las denominadas minorías, cuando, para promoverlas, debe distinguirlas y tratarlas como diferentes.

Ese trato diferenciado, sustentado en categorizaciones específicas, levanta un dejo de crítica que aparece en las representaciones de ciertos estudiantes que ven lo intercultural como referido de modo exclusivo a lo étnico y migrante, y perciben que se deja de lado al grupo de estudiantes que no son identificados con ninguna de estas categorías y, por consiguiente, pueden sentirse discriminados al no ser tratados de manera especial. Así, el espacio de inclusión y respeto a la diferencia propugnado por el proyecto intercultural queda sometido a cuestionamientos por sectores de la comunidad escolar que no lo aprecian como algo transversal en los discursos y las prácticas que desarrolla la institución escolar.

La pluralidad de representaciones que elaboran docentes, educadores tradicionales y estudiantes muestra un espacio educativo donde, cotidianamente, se tensiona la producción de una lógica intercultural. Se superponen estrategias de revaloración y reconocimiento étnico al tiempo que los límites del proyecto intercultural de la escuela parecen confinados a los muros de su institución. Así, algunos actores de la comunidad escolar levantan la voz para alertar sobre los riesgos de ejecutar acciones tan focalizadas que pueden propiciar la formación de un gueto más que el desarrollo de una comunidad intercultural.

En un plano similar, el proceso de revalorización de la diferencia étnica hace emerger un sentido de protección frente a la discriminación que pareciera vincularse a la noción de immunitas (Esposito, 2005) al punto de quedar latente la posibilidad 
de aislarse del entorno social. Ahí, quizá, radica una de las mayores paradojas que presenta este proyecto intercultural: fomentar el reconocimiento de una identidad étnica, apelar a la construcción de un espacio educativo protegido para sus estudiantes, pero quedar restringido al área acotada de la escuela.

De ese modo, surge en las representaciones de los distintos actores una tensión no resuelta entre una perspectiva más funcional de la interculturalidad centrada en fortalecer la identidad de las personas pertenecientes a un pueblo indígena y otra más crítica (Tubino, 2005; Walsh, 2009) que apela a una transformación social más profunda y ampliada a todas las comunidades diversas que conviven en el país.

\section{REFERENCIAS BIBLIOGRÁFICAS}

Abric, J. C. (2001). Prácticas sociales y representaciones. México, DF: Ediciones Coyoacán.

Araya, S. (2002). Las representaciones sociales: ejes teóricos para su discusión. Cuadernos de Ciencias Sociales, vol. 127. Recuperado de http:// www.flacso.or.cr/index.php/publicaciones-jb-br-jb-i-labor-editorial-jb-i/ cuadernos/336-cuaderno-no-127

Catalán, R. (2016). Educación intercultural y representaciones de lo étnico en Chile. Etnografía en un establecimiento secundario en contexto urbano (tesis doctoral). Universidad Complutense de Madrid, España.

Catalán, R. (2013). Prácticas y discursos pedagógicos en Toconao. Cultura, patrimonio e interculturalidad. Estudios Atacameños, núm. 45, pp. 19-40. http:// dx.doi.org/10.4067/S0718-10432013000100003.

Bloul, R. (1999). Beyond ethnic identity: Resisting exclusionary identification. Social Identities, vol. 5, núm. 1, pp. 7-30. https://doi. org/10.1080/13504639951590

Bolados, P. (2006). La educación intercultural atacameña en los procesos étnicos actuales: aproximación, análisis y comprensión de los discursos en los principales agentes que la implementan (tesis de magíster). Instituto de Investigaciones Arqueológicas y Museo, Universidad Católica del Norte, Chile.

Cañulef, E. (1998). Introducción a la educación cultural bilingüe en Chile. Temuco: Instituto de Estudios indígenas, Universidad de la Frontera, serie de Investigaciones 5 .

Cañulef, E. (ed.). (1996). Hacia la interculturalidad y el bilingüismo en la educación chilena. Fundamentos y bases curriculares desde la perspectiva Aymara-atacameña y mapuche. Temuco: Corporación Nacional de Desarrollo Indígena.

Chiodi, F. y Bahamondes, M. (2001). Una escuela, diferentes culturas. Temuco: Corporación Nacional de Desarrollo Indígena.

Del Pópolo, F. (2017). Los pueblos indígenas en América (Abya Yala). Desafíos para la igualdad en la diversidad. Santiago de Chile: Cepal.

Dietz, G. (2003). Hacia una antropología de la interculturalidad. Granada: Editorial Universidad de Granada.

Donoso, A., Contreras, R., Cubillos, L. y Aravena, L. (2006). Interculturalidad y políticas públicas en educación. Reflexiones desde Santiago de Chile. Revista Estudios Pedagógicos, vol. XXXII, núm. 1, pp. 21-31. 
Esposito, R. (2005). Immunitas. Protección y negación de la vida. Buenos Aires: Amorrortu.

Ferrao, V. (2010). Educación intercultural en América Latina. Distintas concepciones y tensiones actuales. Estudios Pedagógicos, vol. 36, núm. 2, pp. 333-342.

Foucault, M. (1987). La historia de la sexualidad I. La voluntad de saber. Madrid: Siglo XXI.

Franzé, A. (2007). Antropología, educación y escuela. Presentación. Revista de Antropología Social, núm. 16, pp. 7-20.

Geertz, C. (1987). La interpretación de las culturas. Barcelona: Gedisa.

Guber, R. (2001). La etnografía: método, campo y reflexividad. Buenos Aires: Norma.

Hall, S. (2003). Introducción: ¿quién necesita identidad? En S. Hall y P. du Gay (eds.). Cuestiones de identidad cultural (pp. 13-39). Buenos Aires: Amorrortu.

Hammersley, P. y Atkinson, M. (2003). Etnografía: métodos de investigación. Barcelona: Paidós.

Hernández, R. (2004). Evaluación de la eficiencia programática y de la pertinencia intercultural del Programa de Educación Intercultural Bilingüe del Ministerio de Educación en escuelas de la región metropolitana. Chile: Departamento de Antropología, Facultad de Ciencias Sociales, Universidad de Chile.

Hevia, R. (ed.) (2005). Políticas educativas de atención a la diversidad cultural: Brasil, Chile, Colombia, México y Perú. Santiago: OREALC/Unesco.

Hymes, D. (2006). ¿Qué es la etnografía? En H. Velasco, J. García y A. Díaz de Rada (eds.). Lecturas de antropología para educadores (pp. 175-192). Madrid: Editorial Trotta.

Jodelet, D. (2003). Pensamiento social e historicidad. Revista Relaciones. Estudios de Historia y Sociedad, núm. 93, vol. XXIV, pp. 99-113. Recuperado de http://redalyc.org/articulo.oa?id=13709305

Jodelet, D. (2000). Develando la cultura. Estudios en representaciones sociales. México, DF: UNAM.

Moscovici, S. (1986). Psicología social II. Pensamiento y vida social. Barcelona: Paidós.

Moscovici, S. (1979). El psicoanálisis, su imagen y su público. Buenos Aires: Editorial Huemul.

Restrepo, E. (2004). Teorías contemporáneas de la etnicidad Stuart Hall y Michel Foucault. Cauca: Editorial Universidad del Cauca.

Rodríguez, T. (2007). Sobre el estudio cualitativo de la estructura de las representaciones sociales. En T. Rodríguez y M. García (eds.). Representaciones sociales. Teoría e investigación (pp. 157-190). Guadalajara: Editorial CUCSH-UDG.

Spivak, G. (2003). ¿Puede hablar el subalterno? Revista Colombiana de Antropología, núm. 39, pp. 301-364.

Stefoni, C., Stang, F. y Riedemann, A. (2016). Educación e interculturalidad en Chile: un marco para el análisis. Estudios Internacionales, núm. 185, pp. 153-182.

Szulc, A. (2009). Becoming neuquino in Mapuzugun: Teaching Mapuche language and culture in the Province of Neuquén, Argentina. Anthropology and Education Quarterly, vol. 40, núm. 2, pp. 129-149. 
Treviño, E., Morawietz, L., Villalobos, C. y Villalobos, E. (2018). Educación intercultural en Chile. Experiencias, pueblos y territorios. Santiago: Ediciones UC.

Tubino, F. (2005, enero). La interculturalidad crítica como proyecto ético-político. Presentado en el Encuentro Continental de Educadores Agustinos, Lima. Recuperado de http://oala.villanova.edu/congresos/educación/lima-ponen-02.html

Velasco, H., García, F. y Díaz de Rada, A. (2006). Lecturas de antropología para educadores. Madrid: Editorial Trotta.

Walsh, C. (2009). Interculturalidad, Estado, sociedad. Luchas (de) coloniales de nuestra época. Quito: Ediciones Abya Yala.

Walsh, C. (2008). Interculturalidad crítica, pedagogía decolonial. En W. Villa y A. Grueso (eds.). Diversidad, interculturalidad y construcción de ciudad. Bogotá: Universidad Pedagógica Nacional/Alcaldía Mayor.

Williamson, G. (2012). Institucionalización de la educación intercultural bilingüe en Chile. Notas y observaciones críticas. Perfiles Educativos, vol. 34, núm. 138, pp. 126-147.

Williamson, G. (2004). ¿Educación multicultural, educación intercultural bilingüe, educación indígena o educación intercultural? Cuadernos Interculturales, vol. 3, pp. 16-24. 